UNIVERSIDADE DE SÃO PAULO

FACULDADE DE MEDICINA DE RIBEIRÃO PRETO

PAULO HENRIQUE MOREIRA ALVES

Diferenciação de angiomiolipomas pobres em gordura de neoplasias renais malignas, com o uso de ressonância magnética multiparamétrica.

Ribeirão Preto

2015 
PAULO HENRIQUE MOREIRA ALVES

\title{
Diferenciação de angiomiolipomas pobres em gordura de neoplasias renais malignas, com o uso de ressonância magnética multiparamétrica.
}

\author{
Dissertação apresentada à Faculdade de \\ Medicina de Ribeirão Preto da Universidade \\ de São Paulo, para a obtenção do título de \\ Mestre em Ciências Médicas. \\ Área de Concentração: Diagnóstico por \\ Imagem.
}

Orientador: Prof. Dr. Valdair Francisco Muglia

Ribeirão Preto

2015 
AUTORIZO A REPRODUÇÃO E DIVULGAÇÃO TOTAL OU PARCIAL DESTE TRABALHO, POR QUALQUER MEIO CONVENCIONAL OU ELETRÔNICO, PARA FINS DE ESTUDO E PESQUISA, DESDE QUE CITADA A FONTE.

\section{FICHA CATALOGRÁFICA}

Alves, Paulo Henrique Moreira

Diferenciação de angiomiolipomas pobres em gordura de neoplasias renais malignas com uso de ressonância magnética multiparamétrica. Paulo Henrique Moreira Alves/ Ribeirão Preto, 2015.

59 páginas, 4 ilustrações, 12 tabelas, 2 gráficos

Dissertação apresentada à Faculdade de Medicina de Ribeirão Preto/USP. Programa: Ciências das Imagens e Física Médica.

Orientador: Muglia, Valdair Francisco

1. Angiomiolipoma pobre em gordura; 2. Carcinoma de células renais; 3. Células claras; 4. Cromófobo; 5 . Papilífero; 6 . Ressonância magnética; 7. Difusão; 8. Teor de gordura 9. Realce; 10. Contraste paramagnético; 


\section{FOLHA DE APROVAÇÃO}

Aluno: Paulo Henrique Moreira Alves

Título: Diferenciação de angiomiolipomas pobres em gordura de neoplasias renais malignas com uso de ressonância magnética multiparamétrica.

Dissertação apresentada à Faculdade de Medicina de Ribeirão Preto da Universidade de São Paulo, para a obtenção do título de Mestre em Ciências Médicas.

Área de Concentração: Diagnóstico por Imagem.

Aprovado em:

Banca Examinadora

Prof. Dr.

Instituição:

Assinatura

Prof. Dr.

Instituição:

Assinatura

Prof. Dr.

Instituição:

Assinatura 


\section{Dedicatóría}

Dedico este estudo à minha família, em especial ao meu avô Alimonino ferreira da Cunha (in memoriam) e minha avó Sebastíana Bonífácio Ferreira, a meus pais Adair Moreira Alves e Eunice María Ferreira Alves e a meus irmãos $\mathcal{A}$ dair Moreira Alves Junior e Thays Ferreira Alves. Dedico também a meus amigos. 


\section{Agradecímentos}

Aos Dr. Jorge Elias Junior e Dr. Valdair Francisco Muglia pela oportunidade do mestrado e por todos os anos de dedicação, ensino e amizade. 
RESUMO 
ALVES, P.H.M. Diferenciação de angiomiolipomas pobres em gordura de neoplasias renais malignas com uso de ressonância magnética multiparamétrica. Dissertação (Mestrado) - Faculdade de Medicina de Ribeirão Preto da Universidade de São Paulo, Ribeirão Preto, 2015.

Introdução: com o uso generalizado de métodos de imagem, aumentou-se a detecção de lesões renais como achados incidentais. Tais lesões podem ser tanto benignas, tais como os angiomiolipomas, e outras malignas, como os carcinomas de células renais, portanto torna-se importante um método nãoinvasivo com boa acurácia para sua distinção . A ultrassonografia é pouco específica para este fim. A tomografia computadorizada e a ressonância magnética são os métodos mais utilizados na caracterização de lesões incidentais renais. Na Ressonância Magnética, o uso de sequências convencionais ponderadas em T2W e T1W, antes e após a administração endovenosa de contraste paramagnético, mostrou-se pouco eficaz para este fim. Técnicas quantitativas associadas às imagens convencionais, tais como a oposição de fase e a restrição a difusão da água, vêm sendo estudadas, devido ao potencial para melhorar a caracterização não-invasiva, evitando nefrectomias parciais ou totais, e outras intervenções invasivas por lesões benignas. Objetivos: avaliar a acuidade diagnóstica de técnicas combinadas de ressonância magnética para diferenciação de angiomiolipomas pobres em gordura de lesões malignas do rim. Métodos: pacientes que obtiveram o diagnóstico histológico das lesões renais entre os anos de 2010 e 2014 e que realizaram exame pré-operatório. As lesões foram estudadas, colocando-se um ROI (region of interest, no inglês) na maior parte da lesão e córtex renal normal, evitando-se área de não-lesões, calculando a intensidade de sinal nas seqüências T1W in e out-phase, T2W, o "Wash in", "Wash out" relativo e absoluto das lesões e o cálculo absoluto do sinal da lesão no ADC (coeficiente de difusão aparente, do inglês). Os resultados foram obtidos na forma de índices padronizados pelo córtex renal e baço, pelas fases pré e pós-contraste, e de forma absoluta pelo ADC. Os resultados foram confrontados com o diagnóstico final e feito associações estatísticas para observar a relevância. Resultados:Foram estudadas 85 lesões em 74 pacientes, sendo 40 do gênero masculino e 34 do feminino. O cálculo do teor de gordura se mostrou ineficaz para distinção entre CCRs e AMLpg; o índice de intensidade de sinal em T2W, lesão/córtex normal foi útil na diferenciação dos CCRs CC de AMLpg. Outro parâmetro importante foi a cálculo de "wash out" relativo que se mostrou mais acentuado no AMLpg que em todos os subtipos de CCRs estudados e da medida do ADC médio, que apresentou valores maiores nos casos de CCR CC, em comparação com os outros subtipos e com os AMLpg. Conclusão: As técnicas combinadas de RM, principalmente o índice de sinal T2W da lesão, "Wash out" relativo e IS do ADC, associados a dados epidemiológicos são viáveis, quando utilizados em conjunto, para a diferenciação de lesões malignas renais dos angiomiolipomas, podendo ter implicações na conduta terapêutica, com redução do número de nefrectomias por lesão benignas. 
Palavras-chaves: Palavras-chave: angiomiolipoma pobre em gordura, carcinoma de células renais, células claras, cromófobo, papilífero, ressonância magnética, difusão, desvio químico, teor de gordura, realce, contraste paramagnético. 
ALVES, P.H.M. Differentiation fat-poor angiomyolipoma of malignant kidney tumors with use of multiparametric MRI sacans $f$. Dissertation (Master) - Ribeirão Preto Medical School, University of São Paulo, Ribeirão Preto, 2015.

Introduction: With the widespread use of imaging methods, detection of incidental renal masses has steadily increased in recent years, and these may be either benign, such as angiomyolipoma, or malignant, such as renal cell carcinomas. Therefore, it is important to have a method that allows accurate characterization. Ultrassonography is not very specific for this purpose. CT and $\mathrm{MRI}$ are the methods used in the characterization of renal incidental lesions. In $\mathrm{MRI}$, the use of conventional sequences, such as T1W and T2W before and after intravenous administration of paramagnetic contrast media, has proved ineffective for this purpose. Quantitative techniques associated with conventional images, such as chemical shift and diffusion weighted imaging (DWI), have played a key role in this differentiation, which aims to improve characterization, avoiding partial or total nephrectomy, and other invasive interventions for benign lesions. Objectives: to evaluate the diagnostic accuracy of combined techniques of MRI to differentiate fat-poor angiomyolipoma from renal cell carcinomas. Methods: Patients who had a histological diagnosis of renal lesions between 2010 and 2014 and underwent pre-operative exam. An ROI (region of interest)cwas placed in most of the lesion and normal renal cortex, avoiding area of non lesions, by calculating the signal intensity in all sequences, in and out phase T1W, T2W, and the wash in, wash out, relative and absolute, of the lesions and estimation of the ADC. The results were obtained in the form of standardized indices for renal cortex and spleen, the pre- and post-contrast phases, and absolute values for ADC. Results were confronted with the final diagnosis and statistical analysis to observe the relevancy. Results: the estimation of intracellular fat content was ineffective for characterization, while the T2W signal intensity index was used for differentiation between CCRs clear cells from fatpoor AML. Another important parameter was the "wash out", which was more prominent for AMLpg. ADC values was higher for CCR CC. Conclusion: We concluded that the combined techniques of MRI mainly T2W signal ratio, "Wash out" and ADC values, when used in association and correlated with epidemiological data may be feasible for the differentiation among fat-poor angiomyolipomas and renal malignancies, with important therapeutics implications, reducing unnecessary nephrectomies for benign lesions.

Keywords: fat-poor angiomyolipoma, renal cell carcinoma, clear cell, chromophobe, papillary, MRI, diffusion, chemical shift, enhancement, paramagnetic. 
Figura 1- Exemplo de lesão no pólo superior do rim onde se pode observar a $\mathrm{ROI}$ de forma poligonal, evitando-se pequena área de aspecto cístico .pag 29

Figura 2- Exemplo de ROI confeccionado sobre a maior área de uma lesão no rim direito, na sequência de difusão aparente.......................................................pag 30

Figura 3- Exemplos de ROls posicionados sobre a lesão e o baço, nas sequências in e out-phase, idênticos, medida para avaliar amostras semelhantes evitando-se viés de posicionamento de ROIs. pag 31

Figura 4- Posicionamento do ROI na sequências pré e pós-contraste, notando-se os ROls idênticos (demonstrados pela área semelhante). pag 32 
LISTA DE TABELAS 
Tabela 1- Número de pacientes e as razões da exclusão do estudo .. pag 28

Tabela 2- Distribuição das lesões por sexo pag 36

Tabela 3- Distribuição das lesões pela faixa etária. pag 36

Tabela 4- Teor de gordura calculado, padronizado pelo baço pag 37

Tabela 5- Teor de gordura calculado de forma absoluta pag 37

Tabela 6- Índice de intensidade de sinal T2W pag 38

Tabela 7- Índice de intensidade de sinal T1W. pag 38

Tabela 8- Comportamento dinâmico das lesões. pag 38

Tabela 9- "Wash out" absoluto pag 39

Tabela 10- Intensidade de sinal das lesões no mapa de ADC pag 40

Tabela 11- Relação interobservador. pag 41

Tabela 12- Critérios diagnósticos pag 42 
LISTA DE GRÁFICOS 
Gráfico 1- Diâmetro médio das lesões .......................................... pag 36

Gráfico 2- Comportamento das lesões pós-contraste....................... pag 41 
LISTA DE SIGLAS E ABREVIATURAS 
CT

Tomografia Computadorizada.

RM

Ressonância magnética

T1W

Sequência Spin Echo, ponderadas em T1

T2W

Sequência Spin Echo, ponderadas em T2

IN PHASE Sequência Gradiente Echo em fase

OUT PHASE Sequência Gradiente Echo fora de fase

CCR Carcinoma de Células Renais

AML Angiomiolipoma

AMLpg Angiomiolipoma pobre em gordura

ADC Coeficiente de difusão aparente das moléculas de água

HCFMRP-USP Hospital das Clínicas da Faculdade de Medicina de Ribeirão Preto da Universidade de São Paulo

CC Variante histológica Células Claras

CF Variante histológica Cromófobo

PP Variante histológica Papilífero

ROI Region of interest 


\section{SUMÁRIO}

1. INTRODUÇÃO pag 20

2. OBJETIVOS .pag 24

3. MATERIAIS E MÉTODOS .pag 26

4.RESULTADOS pag 34

5. DISCUSSÃO .pag 43

6. CONCLUSÕES pag 50

7. REFERÊNCIAS BIBLIOGRÁFICAS pag 52

8. ANEXO .pag 55 


\section{INTRODUÇÃO E JUSTIFICATIVA}


O rim pode ser sede de vários tipos de neoplasias, malignas e benignas, e o uso disseminado de métodos de imagem, como a ultrassonografia e a tomografia computadoriza (TC) tem levado a um aumento na detecção destes tumores de forma incidental. Nestes casos, a maior parte das lesões é de natureza maligna, sendo o carcinoma de células renais (CCR) a mais comum. Entretanto as neoplasia benignas representam cerca de 12 a 20\% das massas renais incidentais (9).

Os angiomiolipomas (AML) representam a neoplasia benigna mais comum correspondendo a mais da metade dos tumores renais benignos (2). A sua incidência na população geral é de 0,3\% (5). Ocorrem de forma esporádica ou associada a certas síndromes, especialmente a esclerose tuberosa e linfangiomatose, onde estão presentes em cerca de 50 a $80 \%$ dos casos (1, 3, 4). A maioria dos AMLs pode ser diagnosticada por métodos de imagem com uma boa acurácia devido ao seu componente de tecido adiposo (gordura macroscópica). Esta detecção pode ser feita por áreas (pixéis agrupados) com atenuação de gordura nos exame de tomografia computadorizada, ou presença do artefato de tinta da china e/ou perda de sinal nas seqüências com supressão de gordura na ressonância magnética $(\mathrm{RM})(3,4,6,7,8)$. Entretanto, cerca de 5 $\%$ dos AML não possuem gordura em quantidade suficiente para ser detectada por estas técnicas, sendo, então, chamados de pobres em gordura (AMLpg). Este grupo de lesões representa um desafio na sua caracterização imagem, principalmente quando são de pequenas dimensões $(6,4)$. E em decorrência da falta de critérios confiáveis por imagem, cerca de 10 a 17\% dos tumores ressecados são benignos, e destes um terço são AMLpg (3).

Os AML incluídos neste grupo apresentam, na maioria das vezes, apenas gordura intracelular. Este tipo de gordura pode ser detectado nas seqüências de RM, na ponderação T1 gradiente eco (GRE) em in-phase e outphase (3), pela perda do sinal na aquisição GRE out-phase, em comparação com a sequência in-phase. Para Kim e al (3), este parâmetro se mostrou eficaz na diferenciação de AML das outras neoplasia renais, utilizando os valores de corte de $25 \%$ no índice de perda de sinal absoluto e - $32 \%$ no índice normalizado pelo baço (1). De maneira oposta, Hindman e al chegaram a conclusão que o uso da 
técnica do desvio químico não é um ferramenta confiável para a diferenciação dos AMLpg das lesões malignas, uma vez que $11 \%$ a $16 \%$ dos CCRs, principalmente os da variante células claras, possuem moderada quantidade de gordura intracelular (2). Outros autores chegaram a números ainda maiores: entre $59-81 \%$ do CCR possuem consideráveis quantidades de gordura intracelular, incluídos ai variantes histológicas cromófobas e células claras $(3,2)$.

$\mathrm{Na} \mathrm{RM}$, a intensidade de sinal em ponderações T2, também foi relacionada, por Sasiwimonphan e al (2), com a presença de gordura intracelular. O sinal da lesão foi comparado com o córtex renal normal, e o achado de hipossinal T2W relativo, foi representativo de AML pobre em gordura (AMLpg).

Os AML, por sua composição (composto de células de músculo liso, gordura e vasos), possuem um comportamento heterogêneo após meio de contraste, principalmente devido ao componente vascular, não específico, portanto, para a diferenciação (13). Kim e al (4), após avaliação por TC, concluíram que os AMLpg tendem a um realce com evolução gradual e prolongada, enquanto os CCR apresentaram um proeminente realce arterial com tendência à "wash out" na fase de equilíbrio, fato observado em $85 \%$ dos casos de CCR e em apenas 32\% do AMLpg. Em outro trabalho semelhante, entretanto com ressonância magnética, Sasiwimonphan e al (2) concluíram que os AMLs e o CCRs apresentaram comportamento semelhante após o uso de meio de contraste paramagnético, todavia os AMLpg apresentaram, no equilíbrio, um maior "wahs out" do meio contraste quando comparado a fase precoce em relação aos RCCs. Em um trabalho mais antigo, realizado por Scialpi e al (14) as lesões malignas e os AML apresentaram uma curva de realce dinâmico diferentes entre si, com os AML apresentando o pico por volta de 30 s e "wash out" posterior, com fases tardias semelhantes as variantes papilífera e cromófoba, e estes por sua vez, apresetavam realce progressivo, com aspecto hipovascular. Todos com curvas bem diferenciando do CC RCC, que mostravam um compartamento hipervascular.

Recentemente, novas técnicas em RM, tais como a difusão, que avalia o movimento browniano das moléculas de água, contribui na caracterização de lesões abdominais, incluindo as renais. Vários centros têm 
pesquisado incessantemente esta ferramenta com intuito de distinguir lesões malignas e benignas. Yoshikawa ET al. e H. Tanaka e al (12) estudaram de forma quantitativa e qualitativa a difusão com "b" em valores crescentes e a intensidade do mapa de ADC (coeficiente de difusão aparente da água) e concluíram que esta análise é útil na diferenciação de neoplasias, uma vez que os CCR tendem a um maior sinal e mais heterogêneo no histograma quando comparado aos AMLs, assegurando-se que o ROI (região de interesse) fosse posicionado para cobrir a maior parte da lesão. Agnello et al e S. Dogonay et al $(9,10)$ concluíram, de forma semelhante, que, em valores de "b" elevados (600 - $1000 \mathrm{~mm}^{2} / \mathrm{s}$ ), as lesões renais os CCR foram hiperintesas em relação aos AMLs, de forma estatisticamente significante, e na análise do mapa de ADC ambas lesões foram hipointensas.

Em um estudo recente, a combinação de técnicas de RM previamente descritas, mostrou possuir uma boa acurácia (2), quando comparado a técnicas isoladas, porém a escassez de dados e resultados controversos, verificados até o momento, justificam a avaliação de uma abordagem multiparamétrica por RM, na caracterização das massas renais. 
2. OBJETIVOS 
São objetivos deste estudo avaliar se a análise combinada de vários parâmetros de ressonância magnética, como restrição a difusão da água, sinal nas sequências $\mathrm{T} 2 \mathrm{~W}$ da lesão, realce pós-contraste paramagnético endovenoso e cálculo do teor de gordura é superior à análise isolada na diferenciação de lesões malignas e dos angiomiolipomas pobres em gordura. 
3. MATERIAL E MÉTODOS 


\subsection{PACIENTES}

Este estudo transversal, observacional e retrospectivo, foi realizado em uma única instituição, Hospital das Clínicas da Faculdade de Medicina de Ribeirão Preto - USP, sendo selecionados todos os casos de massas renais que tiveram confirmação histopatológica, entre os anos de 2010 a 2014, usando como fonte de pesquisa os resultados de biópsia e exames histopatológicos, disponíveis no Departamento de Patologia. Esta pesquisa retornou 115 pacientes, incluindo paciente com tumores renais malignos e angiomiolipomas pobres em gordura.

Utilizamos os seguintes critérios de inclusão no estudo: tumores renais sólidos, sem evidência de gordura macroscópica pelos métodos de imagem, sendo relacionados até duas lesões por paciente no máximo e com diagnóstico histopatológico.

Os critérios de exclusão foram: pacientes que não possuíam exames disponíveis na instituição ou sem RM no pré-operatório; pacientes com lesões acima de $7,0 \mathrm{~cm}$, pois os sinais de agressividade e achados secundários associados (como adenopatia) facilitam a diferenciação diagnóstica; menores que $1,0 \mathrm{~cm}$ por dificultarem o emprego de técnicas quantitativas; e pacientes com lesões predominantemente cística.

Após as exclusões (tabela 1), restaram 74 pacientes, que constituíram a amostra estudada. Destes pacientes, 11 apresentavam mais de uma lesão elegível para o estudo, totalizando 85 lesões renais. 


\begin{tabular}{cl}
\hline Número de pacientes & Motivo da exclusão do estudo \\
\hline $\mathbf{2 1}$ & Lesões acima dos limites de inclusão $(7,0 \mathrm{~cm})$ \\
$\mathbf{7}$ & Não realizaram exame de RM pré-operatório \\
$\mathbf{3}$ & Não possuíam o exame disponível para análise \\
$\mathbf{5}$ & A lesão foi classificada como cisto complexo \\
$\mathbf{1}$ & Exame realizado em aparelho diferente do preconizado \\
$\mathbf{1}$ & A lesão estava em um rim transplantado \\
$\mathbf{1}$ & O exame pré-operatório era uma TC \\
\hline
\end{tabular}

Tabela 1. Número de pacientes e as razões da exclusão do estudo

\subsection{PROTOCOLO DE RM}

Todos os pacientes elegíveis realizaram exames de RM em aparelho de campo fechado, com bobina para abdome, com campo de 1,5 T (Philips Achieva 16 canais, Best, The Netherlands ${ }^{\mathrm{tm}}$ ) com as seguintes sequências: T2 FSE com TE de 80 a 160 ms, TR variáveis, espessura do corte de 7,0 mm, T1 FSE GRE com TE de 2,3 e 4,6 ms (in e out phase) e TR de $118 \mathrm{~ms}$, com espessura de 7,0 mm; Difusão com valores de B variando 20; 500; 1000 mm²/s, e mapa de difusão aparente com espessura de 5,0 mm, T1WIP GRE sense com TE de 1,8 ms e TR de 3,9 ms, com saturação de gordura na fase pré-contraste, e nas fases pós administração de contraste paramagnético em bolus $(0,1$ $\mathrm{mmol} / \mathrm{ml}$ ), com aquisição arterial (atraso de $40 \mathrm{~s}$ ), portal (atraso de $60 \mathrm{~s}$ ) e equilíbrio (atraso de $140 \mathrm{~s}$ ), todos com espessura de 4,0 mm. Todas as sequências utilizadas foram axiais.

\subsection{ANÁLISE QUANTITATIVA}


A análise quantitativa foi realizada por dois observadores independentes, com experiência de 4 anos, cada um, em radiologia e imagens do abdome e sem conhecimento do diagnóstico final. Todos os exames foram examinados no software Osirix®. A região de interesse (ROI) foi posicionada e desenhada de forma poligonal no maior eixo da lesão, sendo evitadas áreas císticas/necrose e calcificações, quando possível, no sentido de aproveitar a maior área possível da lesão (figura 1), sendo observada a intensidade de sinal em seu valor médio de forma absoluta.

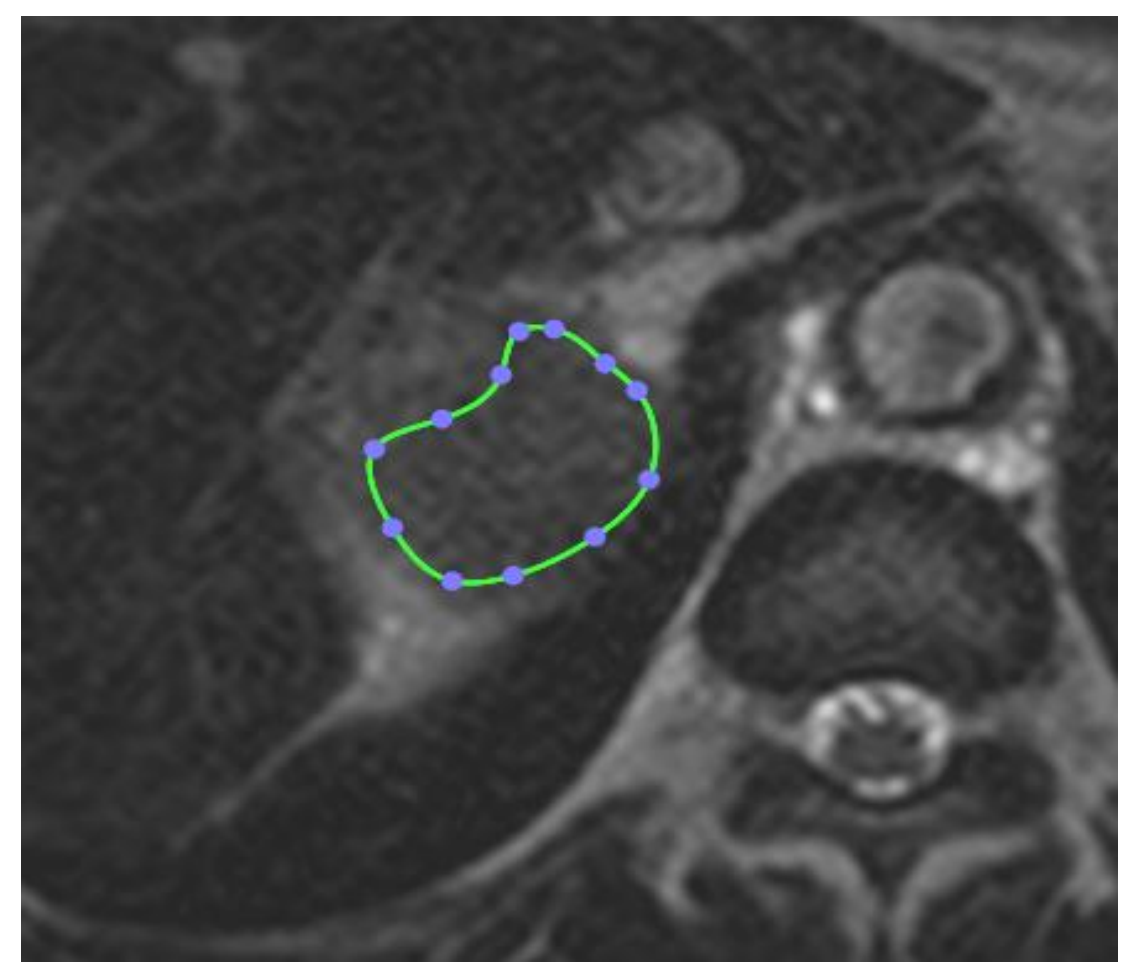

Figura 1. Exemplo de lesão no pólo superior do rim direto onde se pode observar a ROI de forma poligonal, evitando-se pequena área de aspecto cístico.

Para a análise do coeficiente de difusão aparente, dividiu-se as lesões em menores ou iguais a $3 \mathrm{~cm}$ e maiores que $3 \mathrm{~cm}$ no maior eixo. Para as lesões menores, posicionamos apenas ROI na maior área da lesão (figura 2), no 
segundo caso, fizemos três ROI, sendo um na maior área da lesão; outro na linha que dividia igualmente a metade superior e o mesmo para a metade inferior. Neste caso, utilizou-se a média aritmética da intensidade de sinal média dos ROls e o valor foi expresso em $\times 10^{-3}$.

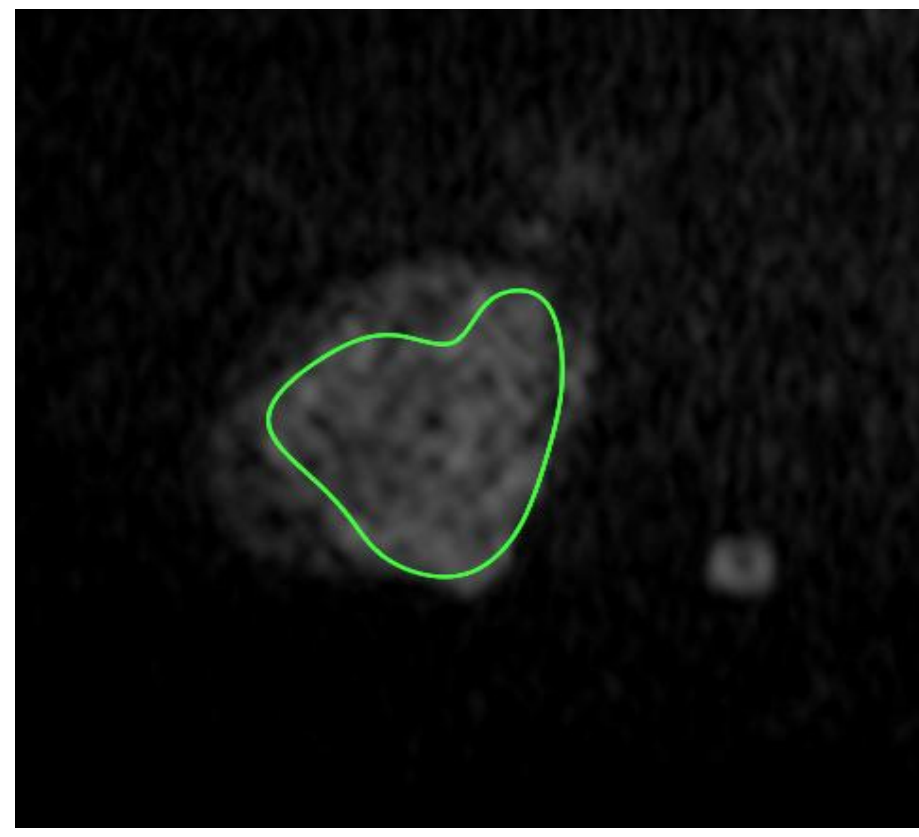

Figura 2. Exemplo de ROI confeccionado sobre a maior área de uma lesão no rim direito na sequência de ADC.

As lesões foram medidas em seu maior eixo axial na seqüência T2W FSE, e esse valor foi utilizado como representativo das dimensões da lesão. Também se obteve a análise do sinal do córtex renal normal, com colocação de uma ROI em área representativa do córtex renal normal, sendo em alguns casos relacionado o rim contralateral da lesão. Realizou-se, também, mensuração da IS do baço em fase e fora de fase. Para a análise nas sequências em fase e fora 
de fase, utilizamos ROls idênticos (figura 3), sendo usados os mesmos critérios na análise do baço e da lesão nas fases pré e pós-contraste (figura 4), na tentativa de se evitar viés de posicionamento de ROI.

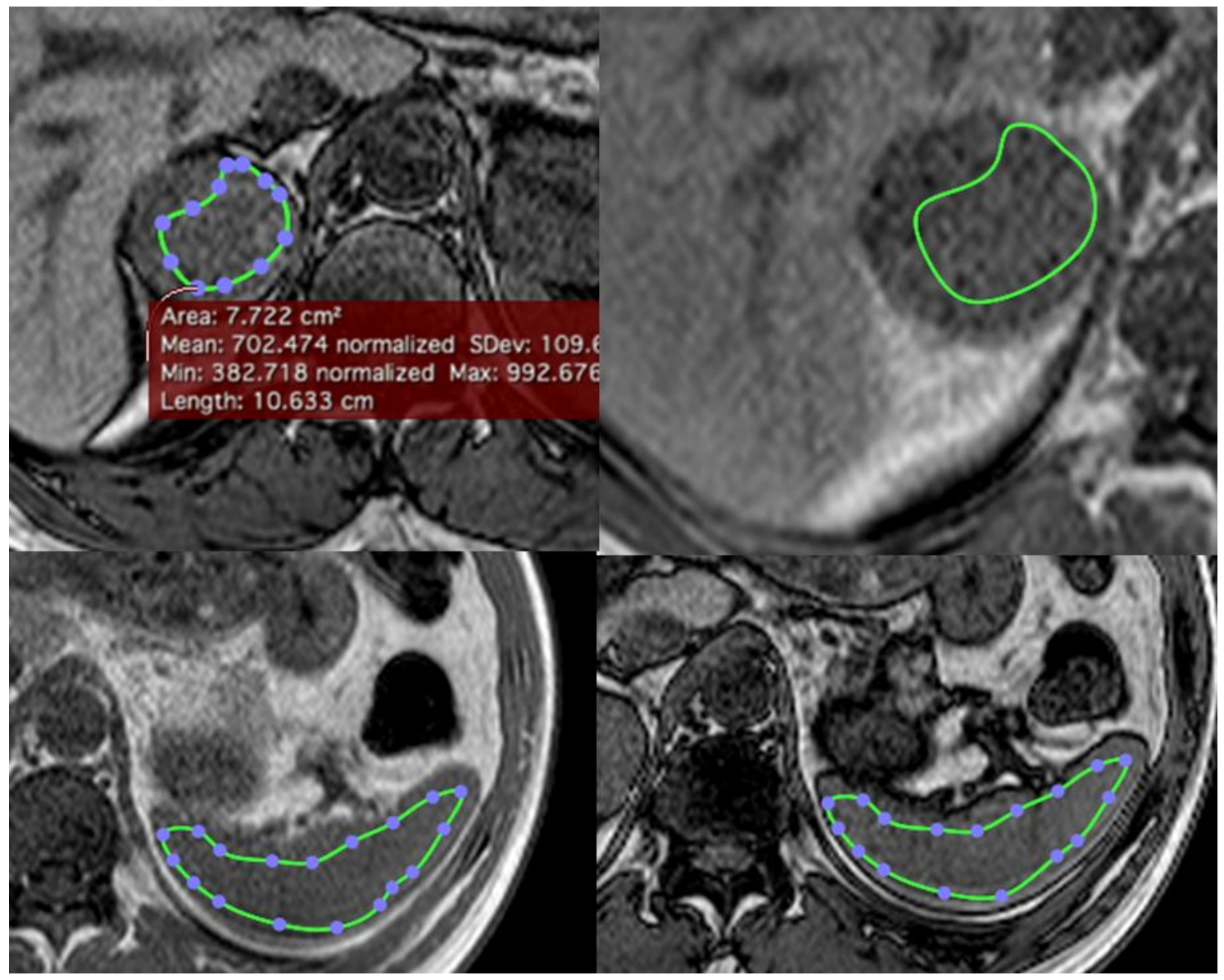

Figura 3. Exemplos de ROls posicionados sobre a lesão e o baço, nas sequências in e outphase, idênticos, medida usada para avaliar amostras semelhantes, evitando-se viés de posicionamento de ROls. Notar, também na imagem superior à esquerda, o quadro informativo da intensidade de sinal, no qual utilizamos a média da intensidade de sinal da amostra, descrito como mean. 


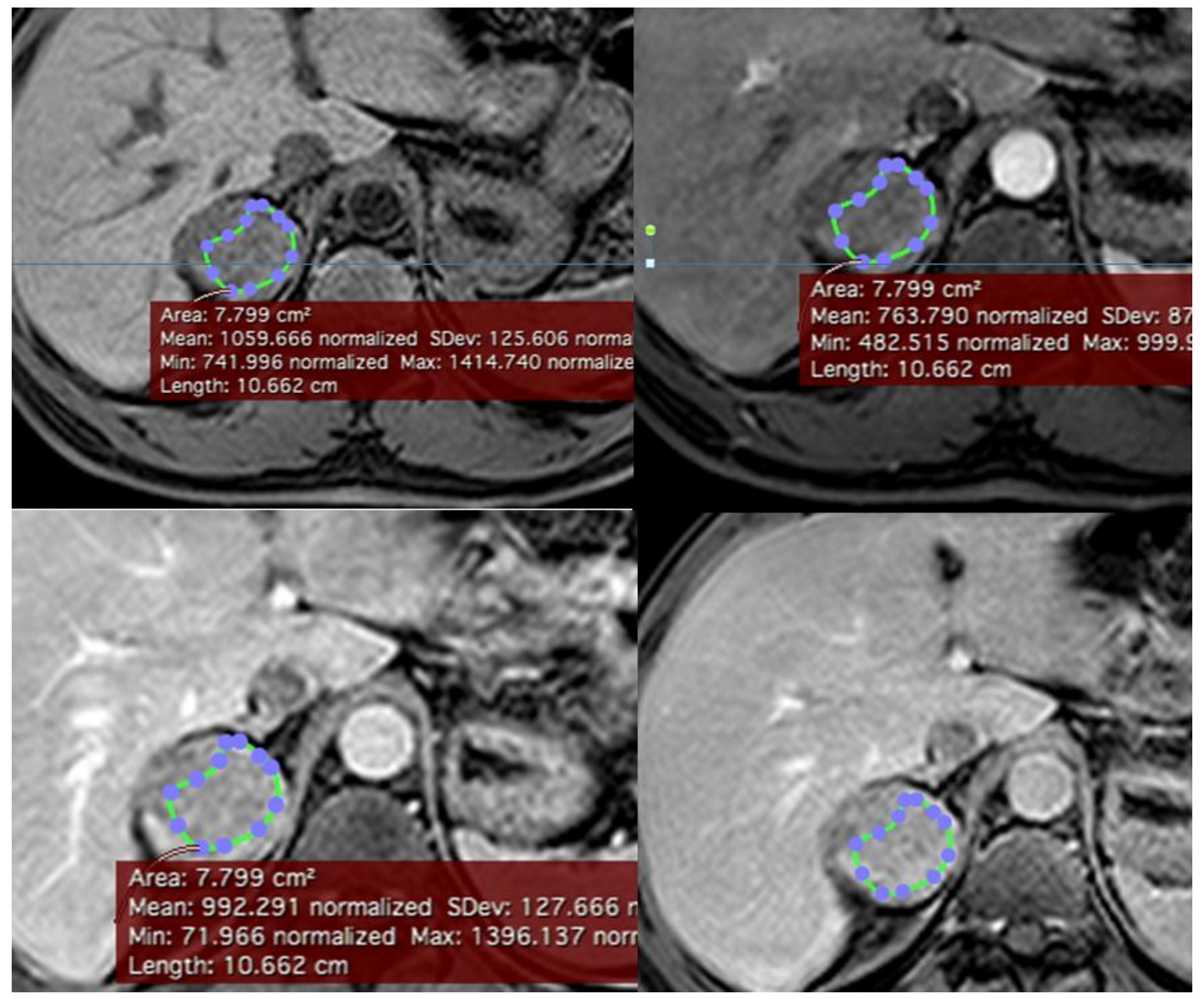

Figura 4. Posicionamento do $\mathrm{ROI}$ na sequências pré e pós-contraste, notando-se os ROls idênticos (demonstrados pela área semelhante), posicionados em cortes equivalentes, nas sequências T1 Fast Spin Echo, com saturação de gordura nas fases pré-contraste (superior a esquerda), arterial (superior a direita), portal (inferior a esquerda) e equilíbrio (inferior a direita).

As medidas foram utilizadas de forma absoluta para obtenção de índices. Foi utilizado o índice de queda de sinal nas sequência em oposição de fase [(IS em fase - IS fora de fase)/IS em fase], normalizadas pela intensidade de sinal do baço $\{[($ IS fora de fase/Baço fora de fase) $] /$ (IS em fase/Baço em fase)]\}. A intensidade de sinal da Lesão em relação ao córtex renal na sequências ponderadas em T1 e T2 [(IS lesão/IS córtex)]. O realce arterial da lesão "wash in" [(IS arterial - IS pré)/ IS arterial) x 100], a depuração relativa "wash out" $\{[($ IS art - IS equilíbrio)/IS equilíbrio] x 100\} e depuração absoluta \{[(IS 
arterial-IS equilíbrio)/(IS equilíbrio - IS pré)] x 100\}. O mapa de difusão aparente foi utilizado de forma absoluta, como foi medido.

\subsection{ANÁLISE HISTOPATOLÓGICA}

Os parâmetros quantitativos obtidos foram confrontados com os diagnósticos histopatológico das lesões, obtidos em todos os casos de lesões malignas e em 10 casos de angiomiolipoma. Em cinco pacientes com esclerose tuberosa, analisou-se uma segunda lesão com as mesmas características de uma previamente ressecada e comprovada como $\mathrm{AML}$, e adotando o diagnóstico presuntivo de AML, após seguimento de pelo menos 36 meses, sem alteração significativa, no tamanho e aspecto interno da massa.

\subsection{ANÁLISE ESTATÍSTICA}

Os dados coletado foram inseridos em uma tabela confeccionada especialmente para o estudo na plataforma Microsoft Excel®, para a análise dos dados.

Considerou-se, para fins estatíticos, o nível de significância de 0,05. 
4. RESULTADOS 
No total foram analisados 74 casos, desses 40 (54\%) eram do sexo masculino e $34(45,9 \%)$ eram do sexo feminino. Onze deles apresentavam mais de uma lesão, totalizando 85 lesões. Destas, 39 (52\%) eram carcinoma de células renais da variante células claras, 12 (16,2\%) variante papilífera e 8 $(10,81 \%)$ da variante cromófoba. Das lesões analisadas, em 15 pacientes (20,27\%) o diagnóstico foi de angiomiolipomas pobres em gordura (AMLpg).

A distribuição das lesões conforme gênero (tabela 2) não evidenciou diferença para os carcinomas das células renais, entretanto os AMLpgs foram mais freqüentes no sexo feminino, com relevância estatística. Em relação à faixa etária, dividimos como base 40 e 65 anos (tabela 3), sendo que os carcinomas de células renais não apresentaram diferença significativa em sua distribuição nas faixas etárias, entretanto os AMLpg demonstraram ser estatisticamente mais comum abaixo dos 40 anos.

A análise do diâmetro médio das lesões (discriminados no gráfico 1) evidenciou que os AMLpg apresentaram uma diferença estatisticamente significante, sendo menor que as variantes Células claras e Cromófobo, não sendo visualizado diferença quando relacionados a variante. Entre as variantes histológicas dos carcinomas de células renais, nota-se diferença estatística entre a variante cromófoba, que tende a ser maior, em relação as variantes células claras e papílefero, entre estes dois últimos não houve diferença significativa. 
Não houvetambém diferença significativa entre os sexos quanto ao tamanho dos

Tabela 2. Distribuição das lesões por sexo

\begin{tabular}{llllll}
\hline \multicolumn{1}{c}{ Sexo } & Células claras & Papilífero & Cromófobo & \multicolumn{2}{c}{ AMLPpg } \\
\hline Maculino & $25(21,1 \%)$ & $10(6,5 \%)$ & $2(4,3 \%)$ & $3(8,1 \%)$ & \\
Feminino & $14(17,9 \%)$ & $2(5,5 \%)$ & $6(3,7 \%)$ & $12(6,9 \%)$ & 15 \\
\hline Total & \multicolumn{2}{c}{39} & 12 & 8 & 1 \\
\hline \multicolumn{2}{c}{ AMLpg: angiomiolipoma pobre em gordura. }
\end{tabular}

Tabela 3 - Distribuição das lesões pela faixa etária

\begin{tabular}{cccccc}
\hline Idade & $\begin{array}{c}\text { Células } \\
\text { claras }\end{array}$ & $\begin{array}{c}\text { Papilífer } \\
\mathbf{0}\end{array}$ & $\begin{array}{c}\text { Cromófob } \\
\mathbf{0}\end{array}$ & AMLpg & Total \\
\hline $\begin{array}{c}\text { Abaixo dos } \\
\mathbf{4 0} \text { anos }\end{array}$ & 4 & 0 & 0 & 13 & 17 \\
$\begin{array}{c}\text { Entre } 40 \text { e } 65 \\
\text { anos }\end{array}$ & 22 & 8 & 6 & 2 & 38 \\
Acima de 65 & 13 & 4 & 2 & 0 & 19 \\
\hline
\end{tabular}

Grafico 1 - Diâmetro Médio das Lesões

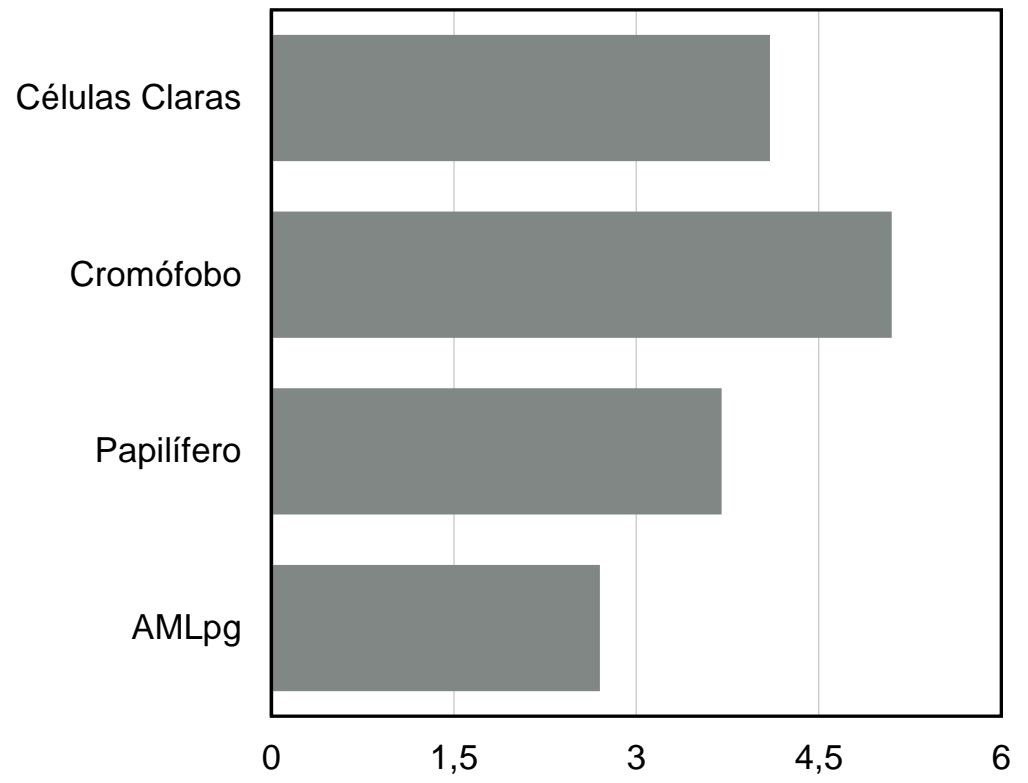

tumores.

A análise do desvio químico para determinar o teor de gordura, obteve os dados de forma padronizadas pela intensidade de sinal do baço e absoluta (tabelas 4 e 5 respectivamente).Não se observou diferença estatística no teor de 
gordura intracelular entre as lesões malignas e os AMLpg, ou mesmo entre as variantes dos carcinomas de células renais.

Tabela 4. Teor de gordura calculado padronizado pelo baço

\begin{tabular}{lccccc}
\hline Lesão & Lesões & Media do IIS & Desvio Padrão & Min & Max \\
\hline Células Claras & 39 & 842 & 214 & 824 & 1197 \\
Cromófabo & 8 & 959 & 105 & 736 & 1052 \\
Papilífero & 12 & 885 & 191 & 469 & 1154 \\
AMLpg & $14^{*}$ & 902 & 215 & 301 & 1120 \\
\hline
\end{tabular}

${ }^{\star}$ Um paciente sem o baço

Tabela 5. Teor de gordura intracelular, calculado de forma absoluta

\begin{tabular}{lccccc}
\hline Lesão & Lesões & Media do IIS & Desvio Padrão & Min & Max \\
\hline Células Claras & 39 & 12.956 & 21.22 & -23.27 & 89.37 \\
Cromófabo & 8 & 3.78 & 7.9 & -6.8 & 19.03 \\
Papilífero & 12 & 9.79 & 15.95 & -11.10 & 51.21 \\
AMLpg & 15 & 11.46 & 19.03 & -5.4 & 70.69 \\
\hline
\end{tabular}

Na medida do índice de intensidade de sinal da lesão, comparada ao córtex, nas sequências ponderadas em $\mathrm{T} 1$ em fase e na sequência ponderada em T2 (discriminadas nas tabelas 6 e 7, respectivamente), observou-se que 0 sinal dos AMLpg tendem a ser menor de forma estatisticamente significativa quando comparadas a variante Papilífera dos carcinomas de células renais nas ponderações em $T 1$, não se observando diferença significativa quando comparadas às demais variantes. Entre os CCRs, a variante Células Claras, apresenta diferença significativa em relação a variante Papilífera

Quando analisamos o sinal na ponderação T2 em relação ao córtex renal, há diferença estatisticamente significativa quando comparamos os sinal AMLpg em relação a variante Células Claras. Entre as demais variantes 
histológicas dos CCRs, as do subtipo Células Claras tendem a ter um sinal maior em T2W ,quando comparadas as variantes cromófoba.

Tabela 6. Índice de intensidade de sinal T2W

\begin{tabular}{lccccc}
\hline Lesão & Lesões & Media do IIS & Desvio Padrão & Min & Max \\
\hline Células Claras & 39 & 1,139 & 0,453 & 0,548 & 2,393 \\
Cromófabo & 8 & 0,851 & 0,230 & 0,637 & 1,364 \\
Papilífero & 12 & 0,908 & 0,513 & 0,351 & 2,015 \\
AMLpg & 14 & 0,812 & 0,429 & 0,322 & 1,951 \\
\hline
\end{tabular}

Tabela 7. Índice de intensidade de sinal T1W

\begin{tabular}{lccccc}
\hline Lesão & Lesões & Media do IIS & Desvio Padrão & Min & Max \\
\hline Células Claras & 39 & 1,034 & 0,253 & 0,463 & 1,705 \\
Cromófabo & 8 & 1,035 & 0,138 & 0,836 & 1,195 \\
Papilífero & 12 & 1,173 & 0,177 & 0,961 & 1,631 \\
AMLpg & 14 & 1,001 & 0,232 & 0,584 & 1,576 \\
\hline
\end{tabular}

No estudo dinâmico pós-contraste foram obtidos o "wash in" (realce arterial) e os dados obtidos (tabela 7) não demonstraram diferença significativa dos AMLpg em relação a qualquer das variantes histológicas dos CCRs. Notouse, apenas, diferença estatística entre as variantes histológicas Células Claras e papilífera, sendo que a primeiro apresenta maior "wash in". O cálculo do "wash out", de forma relativa (tabela 8), demonstrou uma importante diferença estatística entre os AMLpg quando comparados à todas as três variantes histológicas dos carcinomas de células renais. Neste caso, nota-se que os AMLpg tendem a fazer um verdadeiro "wash out" relativo, fato este que não foi 
observado nas variantes dos carcinomas de células renais, que nas fases tardias mostraram tendência a manter ou aumentar o realce. Entre as variantes histológicas dos CCR, não se observou diferença significativa, apesar de uma tendência a menos realce tardio da variante células claras, em relação aos papilíferos e cromófobos.

Em relação ao "wash out" absoluto (discriminado na tabela 9), observou-se diferença significativa entre os AMLpg e a variante papilífera, sendo que a última apresenta um maior "wash out" absoluto. Este fato não foi identificado com as outras variantes. Entre as variantes histológicas, a única associação foi identificadaentre os papilíferos e células claras, notando-se um maior "wash out" no primeiro.

Em relação ao coeficiente de difusão aparente das moléculas de água, nota-se uma diferença significativa entre a variante células claras e os AMLpg, sendo maior para os primeiros. Entre as variantes histológicas, nota-se uma diferença significativa entre papilíferos e células claras, maior no segundo. Entre as demais variantes histológicas e os AMLpg, não houve diferença significativa.

Tabela 8. Comportamento dinâmico das lesões

\begin{tabular}{lcc}
\hline Lesões & wash in (média) & wash out (média) \\
\hline Células Claras & 33,979 & $-7,495$ \\
Cromófabo & 25,815 & $-15,174$ \\
Papilífero & 17,843 & $-13,438$ \\
AMLpg & 29,733 & 7,161 \\
\hline
\end{tabular}


Tabela 9. Wash Out absoluto.

\begin{tabular}{lc}
\hline Lesões & “wash Out” absoluto \\
\hline Células Claras & $-25,648$ \\
Cromófabo & $-39,288$ \\
Papilífero & $-82,860$ \\
AMLpg & $-31,077$ \\
\hline
\end{tabular}

Tabela 10. Intensidade de sinal absoluto das lesões no ADC

\begin{tabular}{lccccc}
\hline Lesões & Lesões & Media do ADC & Desvio Padrão & Min & Max \\
\hline Células Claras & $35^{*}$ & 1,298 & 0,409 & 0,000 & 1,999 \\
Cromófabo & $7^{*}$ & 1,217 & 0,229 & 0,875 & 1,809 \\
Papilífero & $7^{*}$ & 0,957 & 0,292 & 0,650 & 1,458 \\
AMLpg & 15 & 1,081 & 0,337 & 0,376 & 1,925 \\
\hline \multicolumn{2}{c}{$* 1$ exame não possuia ADC }
\end{tabular}


Tabela 11. Comparação inter-observador

\begin{tabular}{ccccccccccc}
\multicolumn{1}{c}{ Observador1 } & \multicolumn{1}{c}{ Observador 2 } \\
\hline Histologia & Maior Eixo & $\mathbf{p}$ & $\mathbf{p}$ & $\mathbf{p}$ & Histologia & Maior Eixo & $\mathbf{p}$ & $\mathbf{p}$ & $\mathbf{p}$ \\
\hline Células Claras & 4.77 & & & & Células Claras & 4.34 & & & \\
Papilífero & 5.66 & 0.12 & & & Papilífero & 5.1 & 0.13 & \\
Cromófobo & 3.95 & 0.22 & 0.03 & & Cromófobo & 3.72 & 0.29 & 0.04 \\
AML & 2.71 & 0.002 & 0.00001 & 0.10 & AML & 2.7 & 0.006 & 0.001 & 0.11
\end{tabular}

\begin{tabular}{ccccccccc}
\hline Indice Em/Fora & Razão & $\mathbf{p}$ & & & Indice Em/For a & Razão & $\mathbf{p}$ & \\
\hline Células Claras & 9.6 & & & & Células Claras & 9.69 & & \\
Papilífero & 4.76 & 0.45 & & & Papilífero & 4.14 & 0.27 \\
Cromófobo & -1.2 & 0.15 & 0.49 & & Cromófobo & 1.45 & 0.16 & 0.69 \\
AML & 19.22 & 0.10 & 0.05 & 0.01 & AML & 2.36 & 0.11 & 0.75 \\
\end{tabular}

\begin{tabular}{ccccccccccc}
\hline Índice Les/Baço & Razão & $\mathbf{p}$ & $\mathbf{p}$ & $\mathbf{p}$ & Índice Les/Baço & Razão & $\mathbf{p}$ & $\mathbf{p}$ & $\mathbf{p}$ \\
\hline Células Claras & 0.88 & & & & Células Claras & 0.91 & & & \\
Papilífero & 0.95 & 0.30 & & & Papilífero & 0.95 & 0.53 & \\
Cromófobo & 1.00 & 0.15 & 0.62 & & Cromófobo & 0.98 & 0.41 & 0.80 \\
AML & 0.84 & 0.43 & 0.13 & 0.06 & AML & 0.99 & 0.19 & 0.62 & 0.86
\end{tabular}

\begin{tabular}{cccccccccc}
\hline Sinal Les/CorT2 & \multicolumn{7}{c}{ Sinal Les/CorT2 } \\
\hline Células Claras & 1.13 & & & Células Claras & 1.03 & \\
Papilífero & 0.90 & 0.03 & & & Papilífero & 0.82 & 0.02 \\
Cromófobo & 0.86 & 0.03 & 0.78 & & Cromófobo & 0.89 & 0.20 & 0.55 \\
AML & 0.65 & 0.0001 & 0.05 & 0.15 & AML & 0.60 & 0.00001 & 0.83 & 0.01
\end{tabular}

\begin{tabular}{ccccccrrr}
\hline Sinal Les/CorT1 & \multicolumn{9}{c}{ Sinal Les/CorT1 } \\
\hline Células Claras & 0.97 & & & Células Claras & 0.95 & \\
Papilífero & 1.21 & 0.02 & & Papilífero & 1.05 & 0.22 & 0.22 \\
Cromófobo & 1.01 & 0.71 & 0.16 & & Cromófobo & 0.92 & 0.70 & 0.22 \\
AML & 1.06 & 0.34 & 0.20 & 0.73 & AML & 0.93 & 0.80 & 0.21 \\
\end{tabular}

\begin{tabular}{|c|c|c|c|c|c|c|c|c|c|}
\hline Wash out Relat. & & & & & Wash out Relat. & & & & \\
\hline Células Claras & $(-) 12.8$ & & & & Células Claras & $(-) 7.25$ & & & \\
\hline Papilífero & $(-) 17.2$ & 0.59 & & & Papilífero & $(-) 13.7$ & 0.42 & & \\
\hline Cromófobo & $(-) 3.0$ & 0.31 & 0.20 & & Cromófobo & 2.51 & 0.30 & 0.14 & \\
\hline AML & 12.91 & 0.001 & 0.002 & 0.14 & AML & 7.52 & 0.05 & 0.02 & 0.63 \\
\hline
\end{tabular}

\begin{tabular}{|c|c|c|c|c|c|c|c|c|c|}
\hline Wash out Absol. & & & & & Wash out Absol & & & & \\
\hline Células Claras & $(-) 34.1$ & & & & Células Claras & $(-) 15.3$ & & & \\
\hline Papilífero & $(-) 42.6$ & 0.85 & & & Papilífero & $(-) 35.9$ & 0.66 & & \\
\hline Cromófobo & $(-) 39.0$ & 0.92 & 0.95 & & Cromófobo & $(-) 19.4$ & 0.94 & 0.80 & \\
\hline AML & $(-) 31.0$ & 0.70 & 0.88 & 0.85 & AML & $(-) 30.0$ & 0.73 & 0.91 & 0.86 \\
\hline
\end{tabular}

\begin{tabular}{cccccccccc}
\hline ADC médio & \multicolumn{7}{c}{ ADC médio } \\
\hline Células Claras & 0.99 & & & Células Claras & 1.32 & \\
Papilífero & 0.55 & 0.04 & & & Papilífero & 0.97 & 0.01 & 0.06 \\
Cromófobo & 0.91 & 0.73 & 0.21 & & Cromófobo & 1.29 & 0.82 & 0.06 \\
AML & 0.97 & 0.89 & 0.10 & 0.83 & AML & 0.97 & 0.01 & 0.97 & 0.02
\end{tabular}


Tabela 12. Critérios diagnósticos

\begin{tabular}{lcccc} 
& \multicolumn{2}{c}{ Observador 1 } & \multicolumn{2}{c}{ Observador 2 } \\
\cline { 2 - 5 } pgAMLs vs ccCCR & Sensibilidade & Especificidade & Sensibilidade & Especificidade \\
(razão T2-L/C + WOR) & $86,7 \%$ & $97,3 \%$ & $93.3 \%$ & $94.6 \%$ \\
pgAMLs vs ppCCR & $(57,5-97.9)^{*}$ & $(85,8-99,5)$ & $(68,0-98,9)$ & $(81,8-99,2)$ \\
(razão T2-L/C + WOR) & $86.7 \%$ & $100 \%$ & $93.3 \%$ & $91.7 \%$ \\
pgAMLs vs cr CCR & $(59,5-97,9)$ & $(73,3-100,0)$ & $(68,0-98,9)$ & $(61,5-98,6)$ \\
(razão T2 - L/C + IIS) & $86,7 \%$ & $87,5 \%$ & $93,3 \%$ & $100 \%$ \\
\hline T2-L/C>0.9 WOR $>10 \% \quad$ IIS-CS>10\% & * "números entre parêntese - Intervalo de Confiança de $95 \%$ & $(62,9-100,0)$ \\
\hline
\end{tabular}


O diagnóstico das lesões renais no pré-operatório ainda é uma tarefa desafiadora, visto a quantidade de lesões benignas que ainda são ressecadas. Alguns métodos de imagem têm sido propostos para esse fim. O mais estudado até o momento,é a deteç̧ão de mínimas quantidade de gordura nos exames de CT (tomografia computadorizada) (4). Com o avanço dos exames em ressonância magnética, tornou-se necessário definir parâmetros para essa detecção, vistos que este método possibilita a utilização de diferentes técnicas, gerando uma melhor acurácia diagnóstica. A principal técnica proposta por vários centros e grupos é o cálculo do teor de gordura intracelulardas lesões, pelo desvio químico. A principio, Kim et al (1) propuseram que este cálculo seria útil nesta diferenciação, fato que não foi reproduzido por Hindman e al (3). Em nossas análises, também não observamos uma diferença estatística significativa entre os AMLpg e as variantes histológicas do CCR, que permitisse um diagnóstico confiável. A variante mais comum dos carcinomas de células renais que é o de células claras, pode apresentar alto teor de gordura intracelular. Entretanto em nossa análises, mesmo em relação a outras variantes dos CCR, essa diferença não foi significativa.

Outro técnica, comum nos exames de Ressonância Magnética,é razão entre a intensidade de sinal, nas sequências spin-echo padronizadas entre a lesão e o córtex renal normal (índice de intensidade de sinal). Alguns estudos mostraram que o hipossinal relativo da lesão foi indicativo de AMLpg contra neoplasias renais, abaixo de $0,9(3,2)$. Em nosso estudo, os AMLpg 
apresentaram um hipossinal em relação ao córtex quando comparados a variante células claras. Entretanto, não se observou este achado na diferenciação com as demais variantes analisadas (cromófoba e papilífera), não sendo, portanto, absolutamente eficaz, fato esse que já habia sido observado (2), sendo, portanto, necessário uma avaliação conjunto com outros parâmetros para chegar a uma boa acurácia.

Outra técnica avaliada, foi a razão de sinal em T1, entre as lesões e o córtex normal. Em algumas fontas (2), esse achado foi relevante, contudo, em nossas análises, esse método se mostrou pouco relevante, com apenas uma diferenciação entre as variante papilifera com as demais.

Com o avanço das técnicas de obtenção de imagens rápidas e dos meios de contraste, uma parte significativa dos exames de Ressonância magnética com meio de contraste, foi avalição da intensidade de sinal do rim (córtex e lesões) ao longo de um período específico após a injeção endovenosa. Em alguns órgãos, como mama e fígado, foram estabelecidos critérios diagnósticos definidos para várias lesões focais neoplásica. Esta análise do comportamento hemodinâmico do meio de contraste fez parte do nosso estudo, assim como de outros grupos anteriormente. Kim e al (1) usando exames de tomografia computadorizada e meio de contraste iodado, chegaram a uma associação, mostrando que os AML tendiam a um realce gradual e contínuo nas fases tardias, enquanto os carcinomas de células renais variante células claras, mostraram um comportamento hipervascular com tendência a "wash out". Este estudo se tornou importante ao demonstrar que a dinâmica de realce das lesões são diferentes, entretanto o objeto de nosso estudo são os exames de 
ressonância magnética. Outro grupo, Sciapli e al (14), previamente, trabalhando com ressonância magnética e contraste paramagnético, demonstraram que tanto os carcinomas células claras como AML possuíam importante realce na fase arterial, com pico nos AML após 30s da administração do contraste e comportamento hipervascular do CCR células claras, explicado pela vascularização de ambos, entretanto com "wash out", no caso dos AML, e curva tardia semelhante a variante papilífera. Em estudo recente (2), foi observado que os AML, principalmente a variante pobre em gordura, apresentaram um wash out mais proeminente, quando comparados aos carcinomas renais células claras refletindo os estudo anteriores. Em nosso estudo, observamos achados consistentes com o que foi descrito $(2,14)$, a fase arterial não demonstrou diferença significativa entre qualquer uma das lesões estudadas. No entanto, a medida de "wash out" do meio contraste, mostrou uma clara tendência a ser maior nos AMLpg (estatisticamente significativa), que nas demais lesões renais malignas estudadas (subtipos células claras, papilífero e cromófobo), podendo este ser um importante fator de diferenciação. Este achdo pode ser explicado pelo componente vascular do $\mathrm{AML}$ predominando. $\mathrm{O}$ estudo dinâmico, com "wash out" relativo, em nosso estudo, ao contrário do que foi relatado previamente (13), não demonstrou uma associação significativa para diferenciação dos subtipos de carcinomas de células renais, o que pode ser explicado pelas técnicas diferentes empregados em ambos protocolos. Quando utilizamos o "wash out" absoluto, obtivemos uma associação na diferenciação de subtipos histológicos células claras e papilífero, entretanto não obtivemos 
uma diferenciação significativa em relação aos AMLpg, principal objetivo desse estudo.

Uma das novas ferramentas da RM, de forma geral, é a análise do movimento browniano das moléculas de água com diferentes valores de campo magnético, conhecido como restrição a difusão da água, empregado em todos os aspecto da imagem de abdome. No caso do rim, não temos ainda uma definição em relação a essa ferramenta, e, decorrente disso, nota-se uma crescente quantidade de artigos publicados que pesquisaram essa sequência, principalmente nos últimos 4 anos. Os primeiros estudos não foram conclusivos neste sentido, entretanto o primeiro a mostrar resultado (12), demonstrou não só uma diferença significativa na intensidade de sinal, entre os AMLpg e os CCR na variante células claras como também uma heterogeneidade no ADC, analisados atraves do histograma, sendo esta maior no último. Outro estudo recente (9), demonstrou que para pequenas lesões renais a mensuração do ADC em altos valores de B (600 e $1000 \mathrm{~mm} / \mathrm{s})$ foi significante para diferenciação da agressividade destas lesões, com as lesões malignas renais, principalmente os células claras, se mostrando mais intensas que os AML e AMLpg. Neste estudo também se observou diferença entre outras lesões renais malignas e benignas, e também, que de forma geral, todas foram hipointensas em relação ao córtex renal normal e hipointensas no mapa de ADC, mostrando-se boa resolução para análise das imagens. Uma outra abordagem (10), utilizou um método semelhante ao utilizado neste estudo, demonstrando que, de forma geral, as lesões malignas e benignas renais podem ser diferenciadas pela mensuração da intensidade de sinal do ADC. No entanto, esta última referência não é muito 
especifico, e incluiu outras lesões benignas como, por exemplo, os oncocitomas. No presente estudo, foi utilizado uma abordagem com ROI único para lesões pequenas $(<3 \mathrm{~cm})$ e três ROls para lesões maiores, e calculamos apenas a intensidade de sinal absoluta do ADC, não comparando este com o córtex renal, e obtivemos uma associação significativa quando comparamos os AMLpg com os CCR células claras. O sinal do mapa de ADC, no carcinoma variante células claras, tende a ser maior que os do AMLpg, achados ja previamente relatos nas referências utilizadas. Porém, em relação a diferenciação das outras variantes histológicas do CCR com os AMLpg, não se obteve os mesmos resultados, não sendo estatisticamente significante.

Outros achados associados, mostra-se que os AMLpg são mais freqüentes em mulheres, abaixo dos 40 anos de idade e também as dimensões dos AMLpg mostraram ser menores que os dos carcinomas de células renais.

Outros achados importantes utilizados rotineiramente na análise dos exame de RM, tais como áreas de necrose, invasão venosa e lesões de grandes dimensões foram excluídas de nosso estudo, pois, geralmente, com raríssimas exceções, estão relacionados a lesões malignas, não gerando dúvidas quando a agressividade da lesões.

A discrepância dos dados quando observados os dois observadores diferentes, principalmente quando utilizamos parâmetros bastante sensíveis mostra que o método apresenta baixa reprodutibilidade, sendo o viés de posicionamento de ROI a provável causa. 
6. CONCLUSÕES 
Nossos resultados sugerem que a análise conjunta des parâmetros de imagem tais como o indice de intensidade de sinal T2W, dinâmica de realce e cálculo da intensidade de sinal do ADC, correlacionados com fatores epidemiológicos, descritos no exame como sexo, idade e tamanho da lesão, podem ser capazes de diferenciar parcela significativa das lesões malignas e os angiomiolipomas pobres em gordura em exame pre-operatórios, potencialmente reduzindo o número de lesões benignas que são submetidas a resecção cirúrgica de forma desnecessária. 


\section{REFERÊNCIAS BIBLIOGRÁFICAS}


1. Kim JK, Kim SH, Jang YJ, et al." Renal angiomyolipoma with minimal fat: differentia-tion from other neoplasms at double-echo chemical shift " FLASH MR imaging. Radiology 2006;239(1):174-180.

2. Sasiwimonphan $\mathrm{K}$, Takahashi N, Leibovich BC, Carter RE, Atwell TD, Kawashima A. "Small $(<4 \quad \mathrm{~cm})$ renal mass: differentiation of angiomyolipoma without visible fat from renal cell carcinoma utilizing MR imaging". Radiology. 2012 Apr;263(1):160-8.

3. Hindman N, Ngo L, Genega EM, Melamed J, Wei J, Braza JM, Rofsky NM, Pedrosa. "Angiomyolipoma with minimal fat: can it be differentiated from clear cell renal cell carcinoma by using standard MR techniques?

Radiology. 2012 Nov;265(2):468-77

4. Kim JK, Park SY, Shon JH, Cho KS. "Angiomyolipoma with minimal fat: differentiation from renal cell carcinoma at biphasic helical CT". Radiology 2004;230(3):677-684.

5.Kemaitre L, Claudon M, Dubrulle F, and Mazeman E. "Imaging of Angiomyolipomas". Seminars in Ultrasound, CT, and MRI, Vo118, No 2 (April), 1997: pp 100-114

6. Jinzaki M, Tanimoto A, Narimatsu Y, et al. "Angiomyolipoma: imaging findings in lesions with minimal fat”. Radiology1997;205(2):497-502.

7. Bosniak MA, Megibow AJ, Hulnick DH, Horii S, Raghavendra BN. "CT diagnosis of renal angiomyolipoma: the importance of detecting small amounts of fat". AJR Am J Roentgenol 1988;151(3):497-501.

8. Israel GM, Hindman N, Hecht E, Krinsky G. "The use of opposed-phase chemical shift MRI in the diagnosis of renal angiomyolipomas". AJR Am J Roentgenol 2005;184(6):1868-1872.

9. Agnello F, Roy C, Bazille G, Galia M, Midiri M, Charles T, Lang H." Small solid renal masses: Characterization by diffusion-weighted MRI at 3 T". Clinical Radiology 68 (2013) e301e e308.

10. DoGanay S, Kocakoc E, Cicekc M, Glamis SA, Akpolat N, Orhan I." Ability and utility of diffusion-weighted MRI with different b-values in the evaluation of benign and malignant renal lesions". Clin Radiol. 2011 May;66(5):420-5

11. Yoshikawa $T$, Kawamitsu $H$, Mitchell DG, et al. "ADC measurement of abdominal organs and lesions using parallel imaging technique". Am $\mathrm{J}$ Roentgenol 2006;187:1521-30

12. Tanaka $H$, Yoshida $S$, Fujii $Y$, Ishii $C$, Tanaka $H$, Koga $F$ et al. "Diffusionweighted magnetic resonance imaging in the differentiation of angiomyolipoma with minimal fat from clear cell renal cell carcinoma". International Journal of Urology (2011)18, 727-730 
13.Sun MRM, Ngo L, Genega EM, Atkins MB, Finn ME, Rofsky NM, Pedrosa "Renal Cell Carcinoma: Dynamic Contrast-enhanced MR Imaging forDifferentiation of Tumor Subtypes - Correlation with Pathologic Findings"I Radiology 2009;250(3): 793-802.

14. Scialpi M, Di Maggio A, Midiri M, Loper- fido A, Angelelli G, Rotondo A. "Small renal masses: assessment of lesion characterization and vascularity on dynamic contrast-enhanced MR imaging with fat suppression". AJR Am J Roentgenol 2000;175(3):751-757. 


\section{ANEXOS}




\section{ANEXO A}

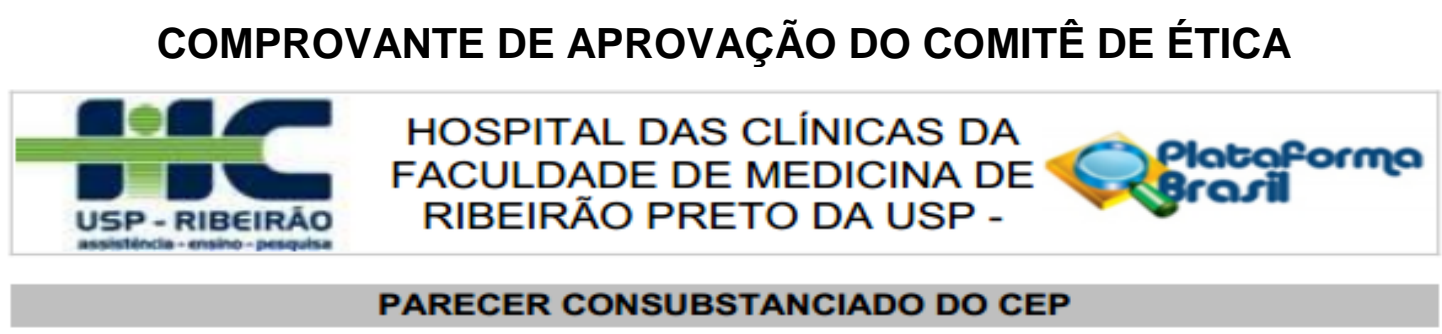

\section{DADOS DO PROJETO DE PESQUISA}

Título da Pesquisa: Diferenciação de angiomiolipomas pobres em gordura de neoplasia renais malignas com uso das técnicas de difusão, oposição de fase e realce pos contraste em Ressonância Magnética.

Pesquisador: PAULO HENRIQUE MOREIRA ALVES

Área Temática:

Versão: 2

CAAE: 37652514.8 .0000 .5440

Instituição Proponente: Hospital das Clínicas da Faculdade de Medicina de Ribeirão Preto da USP -

Patrocinador Principal: Financiamento Próprio

\section{DADOS DO PARECER}

Número do Parecer: 904.256

Data da Relatoria: 09/12/2014

Apresentação do Projeto:

Trata-se de projeto de pesquisa, que não envolve título acadêmico, a ser desenvolvido pelo médico residente Paulo Henrique Moreira Alves, sob orientação do Prof. Dr. Valdair Francisco Muglia da Faculdade de Medicina de Ribeirăo Preto - USP

\section{Objetivo da Pesquisa:}

\section{Objetivo Primário:}

Avaliar se a análise combinada de vários parâmetros de ressonância magnética, como restrição a difusão da água, sinal nas sequências T2W da lesão, realce pós contraste e oposição de fases é superior à análise isolada na diferenciação de lesōes malignas e benignas renais Objetivo Secundário:

A experiência do radiologista exerce efeito sobre a análise das variáveis?

\section{Avaliação dos Riscos e Beneficios:}

Riscos:

Há um risco teórico de exposição e quebra do sigilo do paciente, no entanto serão tomadas precauções como a anonimização para confecção de banco de dados. Não há outros riscos, pois o

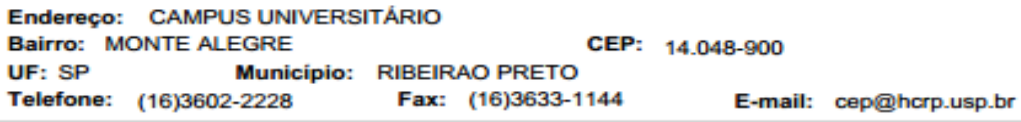




\section{HOSPITAL DAS CLINICAS DA
FACULDADE DE MEDICINA DE Q Plotoformo
RIBEIRÃO PRETO DA USP -}

Continuaçāo do Parecer. 904.256

estudo e retrospectivo e todos os exames já foram realizados e envolveram técnicas de uso corrente e já previamente avaliadas.

Beneficios:

Não há beneficios diretos para os participantes do estudo. No entanto, de acordo os resultados obtidos haverá beneficios para paciente com alteraçōes semelhantes.

\section{Comentários e Considerações sobre a Pesquisa:}

O rim pode ser sede de vários tipos de neoplasias, malignas e benignas, e o uso disseminado de métodos de imagem, como ultrassonografia e TC têm levado a um aumento na detecção destes tumores. A maior parte das lesōes é de natureza maligna, sendo o carcinoma de células renais a mais comum, entretanto as neoplasias benignas representam cerca de 20 a $25 \%$. Os angiomiolipomas (AML) representam neoplasia benigna mais comum, correspondendo a mais da metade dos tumores renais benignos. A sua incidência na população geral é de $0,3 \%$. A maioria dos AMLs pode ser diagnosticada por métodos de imagem com uma boa acurácia devido ao seu componente de gordura macroscópica. Esta detecção pode ser feita por áreas (pixéis agrupados) com atenuação de gordura na tomografia computadorizada, ou presença do artefato de tinta da china e/ou perda de sinal nas sequências com supressão de gordura na RM. Entretanto, cerca de 5 \% dos AML não possui estes achados, sendo, então, chamados de pobres em gordura ou sem gordura macroscópica detectável. Este grupo de lesões representa um desafio na sua caracterização por métodos de imagem, principalmente quando são de pequenas dimensōes. E em decorrência da falta de critérios por imagem confiáveis, cerca de 10 a $17 \%$ dos tumores ressecados são benignos, e destes um terço são $\mathrm{AML}$.

\section{Considerações sobre os Termos de apresentação obrigatória:}

Foram apresentados os seguintes documentos: a) Folha de rosto, assinada pelo pesquisador responsável e pelo Coordenador Técnico da UPC; b) Projeto de Pesquisa, com o orçamento, cronograma do estudo e referências bibliográficas e c) Dispensa do TCLE.

\section{Recomendações:}

O pesquisador atendeu às recomendações deste CEP.

Conclusões ou Pendências e Lista de Inadequações:

Diante do exposto e à luz da Resolução CNS 466/2012, o projeto de pesquisa Versão 3 -

Endereço: CAMPUS UNIVERSITÁRIO

Bairro: MONTE ALEGRE CEP: $14.048-900$

UF: SP Municipio: RIBEIRAO PRETO

Telefone: (16)3602-2228 Fax: (16)3633-1144 E-mail: cep@hcrp.usp.br 


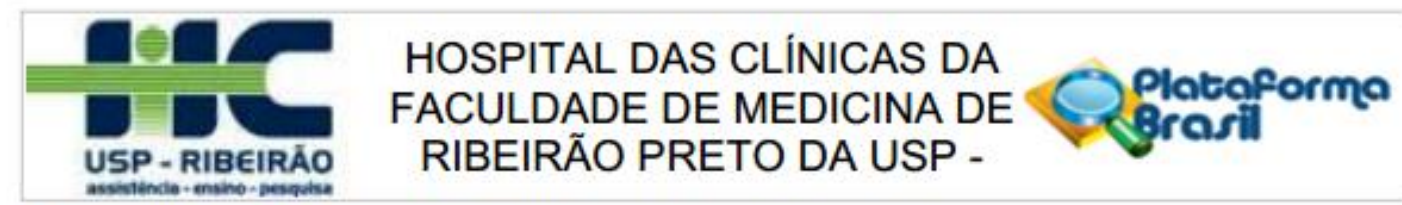

Continuaçẵo do Parecer. 904.256

modificado em 02 de Dezembro de 2014, assim como a solicitação de dispensa de aplicação do Termo de Consentimento Livre e Esclarecido, podem ser enquadrados na categoria APROVADO.

Situação do Parecer:

Aprovado

Necessita Apreciação da CONEP:

Não

Consideraçōes Finais a critério do CEP:

Projeto Aprovado: Tendo em vista a legislaçăo vigente, devem ser encaminhados ao CEP, relatórios parciais anuais referentes ao andamento da pesquisa e relatório final ao término do trabalho. Qualquer modificaçăo do projeto original deve ser apresentada a este CEP em nova versão, de forma objetiva e com justificativas, para nova apreciação.

RIBEIRAO PRETO, 09 de Dezembro de 2014

Assinado por:
MARCIA GUIMARÃES VILLANOVA

(Coordenador)

Endereço: CAMPUS UNIVERSITARRIO

Bairro: MONTE ALEGRE CEP: $14.048-900$

UF: SP Municipio: RIBEIRAO PRETO

Telefone: (16)3602-2228 Fax: (16)3633-1144 E-mail: cep@hcrp.usp.br 


\title{
ANEXO B
}

\section{SOLICITAÇÃO DA DISPENSA DO TERMO DE CONSENTIMENTO LIVRE ESCLARECIDO}

\author{
ANEXO \\ Solicitação de dispensa de obtenção do "Termo de \\ Consentimento Livre e Esclarecido (TCLE)"
}

Ribeirão Preto, 22 de setembro de 2014.

Ref.: Projeto - "Diferenciação de angiomiolipomas pobres em gordura de neoplasia renais malignas com uso das técnicas de difusão, oposição de fase $e$ realce pós contraste em exames de Ressonância Magnética."

Vimos, através desta, solicitar a dispensa de obtenção do "Termo de Consentimento Livre e Esclarecido (TCLE)" para este projeto.

Trata-se estudo retrospectivo que envolve a análise de exames de imagem de cerca de 60 indivíduos, realizados no Centro de Ciências da Imagem e Física Médica (CCIFM) do HC-FMRP-USP. Os exames foram realizados nos anos de 2010 e 2014 com vistas à assitência e diagnóstico.

Não serão realizadas avaliações de prontuários médicos.

Em momento algum, será divulgada a identidade de qualquer paciente.

Desta forma, pelo fato deste projeto não implicar em nenhuma nova intervenção com o paciente e pela impossibilidade de contatarmos todos os envolvidos na amostra, solicitamos a dispensa do TCLE.

Atenciosamente,

Paulo Henrique Moreira Alves

Médico Radiologista Pós-gracuando

Hospital das Clínicas da Faculdade de Medicina de Ribeiriono Preto da Unimersidade de Sta Paulo Centro de Ciências da Inageme Física Médica

Prof Dr. Valdair Francisco Muglia

Médico Docente do Departamento de Clínica Médica

Hospital das Clínicas da Faculdade de Medicina de Riberino Preto da Unimersidade de Stro Paulo

Centro de Ciências da Inagem e Física Médica 